\title{
APPLICATION OF RESPONSE SURFACE METHODOLOGY IN OPTIMIZATION OF PACLITAXEL LIPOSOMES PREPARED BY THIN FILM HYDRATION TECHNIQUE
}

\author{
AMOL A. TATODE ${ }^{1 *}$, ARUN T. PATIL ${ }^{2}$, MILIND J. UMEKAR ${ }^{2}$ \\ 1Department of Pharmaceutics, University Department of Pharmaceutical Sciences, Rashtrasant Tukadoji Maharaj Nagpur University, \\ Nagpur, Maharashtra 440033, India, ${ }^{2}$ Smt Kishoritai Bhoyar College of Pharmacy, Kamptee, Nagpur, Maharashtra 441002, India \\ Email: aatatode@rediffmail.com
}

Received: 12 Dec 2017, Revised and Accepted: 23 Jan 2018

ABSTRACT

Objective: The present investigation was aimed to optimize the formula of paclitaxel-loaded liposomes (PTL) by using the application of response surface methodology (RSM).

Methods: Paclitaxel-loaded liposome (PTL) was optimized by response surface methodology based on two parameters, namely, percent entrapment efficiency (\% EE) and percent in vitro drug release at $12 \mathrm{~h}(\% \mathrm{DR})$. The liposome formula was prepared using $3^{2}$ factorial design, and the selected independent variables were, phospholipid (phospholipon 90G) and cholesterol (CH) concentrations. Nine formulas of paclitaxel-loaded liposome were prepared by thin film hydration technique (THF). The entrapment efficiency, in vitro release studies and drug content, were evaluated using on UV-visible spectrophotometer at $\lambda \max -230 \mathrm{~nm}$. The developed PTL formulation vesicle morphology, particle size, polydispersity index (PDI) and zeta potential (ל) were evaluated by Motic digital microscope and Malvern zetasizer respectively.

Results: Using response surface methodology the estimated coefficient values obtained for independent variables in the regression equations, exhibited that the phospholipid (PL90G) and cholesterol (CH) molar concentration was observed to be highly influencing variables in optimizing \% EE $(86.67 \pm 0.67)$ and $\%$ DR $(63.49 \pm 1.21)$. In the prediction of \% EE and \% DR values, the percent relative errors (PRE) was found to be low ( $-0.290 \%)$ and $(0.058 \%)$ respectively. This suggests that design-developed model was found to be suitable for PTL formulations and thus, validate the model.

Conclusion: Experimental results show that the observed responses were in close agreement with the predicted values and this demonstrates the reliability of the RSM in an optimization of \% EE and \% DR in paclitaxel liposomal (PTL) formulations.

Keywords: Response surface methodology, Paclitaxel, Liposomes, Thin film hydration technique

(C) 2018 The Authors. Published by Innovare Academic Sciences Pvt Ltd. This is an open access article under the CC BY license (http://creativecommons.org/licenses/by/4.0/) DOI: http://dx.doi.org/10.22159/ijap.2018v10i2.24238

\section{INTRODUCTION}

Paclitaxel (PT) is a chemical compound isolated from the bark of Taxus brevifolia (northwest Pacific Yew Tree), empirical formula $\left(\mathrm{C}_{47} \mathrm{H}_{51} \mathrm{NO}_{14}\right)$ and on the basis of characterization named it as Taxol [1]. It has the potential anticancer drug, based on previous reports, PT shows anticancer activities towards breast cancer [2], ovarian cancer [3], lung cancer [4] and pancreatic cancer [5]. However, PT exhibits poor aqueous solubility and permeability owing to biopharmaceutical classification system (BCS) class IV drug, which directs it to low bioavailability. Therefore, by consideration of these problems, there is a need to develop a novel formulation of such effective and efficient anticancer drug.

For improving poor aqueous solubility and permeability of PT, a number of formulation strategies have been developed and used. Some of them were modified, due to some excipient-drug interactions. For improving the solubility, PT dissolved in a mixture of polyoxyethylated castor oil (Cremophore EL): dehydrated ethanol (1:1) ratio as a delivery vehicle. The formulation produced hypersensitivity and non-linear pharmacokinetic behavior after intravenous administration. The hypersensitivity reaction at the site of administration could be due to an inclusion of Cremophore EL [67]. After that, the delivery vehicle was replaced with the addition of tween 80 alone or combination of tween 80: dehydrated alcohol, and diluted with aqueous media. The diluted formulation showed the precipitation of PT from solution due to low solubility [8]. These attempted techniques, with persistent low solubility problem, has been overcome by creating novel formulation with the aim of improving aqueous solubility, permeability, and bioavailability of PT. It includes novel oral formulation [9], novel PT self-emulsifying drug delivery system (SEDDS) [10], novel ligands based PT targeting formulation [11], micellar formulation [12], liposomal formulation [13], bioconjugates [14], dendrimers [15] and nanocarrier systems [16]. In all these formulation techniques the problem associated with PT was shown to be improved significantly.
The liposome is emerging techniques for specialized drug delivery [17] and best suitable for lipophilic drug due to its biocompatibility and reducing drug toxicity, with maintaining efficacy of the anticancer drug for a maximum period of time. Some previous studies include asulacrine [18], docetaxel [19] and tamoxifen [20] with these approaches, their poor aqueous solubility and bioavailability were found to be improved. So, need to develop and optimize the paclitaxel-loaded liposomes (PTL) for effective anticancer treatment. In pharmaceutical technology, in the development and optimization of different pharmaceutical dosage forms, there are a high number of factors which influence the product characteristics. Therefore, complex, expensive and time-consuming formulation studies are often necessary for the development of a product with required and desired properties. The experimental design methodology is a strategy to use a smaller number of experiments and to avoid unnecessary experiments [21-22].

Experiments were designed to determine the effect of the independent variables (factor) on the dependent variable (parameter/response) of a process or formulation. RSM, one of the designs of experiments, is a powerful tool for determining the relationship between a response and a set of quantitative involved factors. RSM is a technique used to find the optimum response by using the quadratic polynomial model [23]. The advantage of RSM is the reduced amount of experiments required, thereby reducing the cost of expensive analysis methods. The application of RSM is useful for understanding or mapping a region of the response surface, finding the variable level of optimum response, and selecting the process condition or formula to meet the specifications [24]. This research was carried out to optimize PTL formula with independent variables such as phospholipid (phospholipon 90G) concentration and cholesterol $(\mathrm{CH})$ concentration. The optimum formula was obtained from RSM using $3^{2}$ full factorial design. The optimization approach was applied to obtain desired \% EE and \% DR for PTL. 


\section{MATERIALS AND METHODS}

\section{Materials}

Paclitaxel (PT), (purity $>90 \%$ ) was received as a gift sample from MAC-CHEM Products (India) Pvt. Ltd. Bhoisar, Thane, India. The phospholipids samples viz., Phospholipon 90G ${ }^{\circledR}$ (PL90G), Phospholipon $80 \mathrm{H}^{\circledR}$ (PL80H) and Phospholipon $90 \mathrm{H}^{\circledR}$ (PL90H) with purity $>90 \%$, was obtained as a free gift sample from Lipoid $\mathrm{GmbH}$, Ludwigshafen, Germany. The solvents namely chloroform and methanol were purchased from Merck Ltd. Mumbai, India. Cholesterol $(\mathrm{CH})$, potassium dihydrogen phosphate and sodium hydroxide pellets were obtained from Sigma Chemicals, SigmaAldrich Corporation, St. Louis, MO. Chemical used in this work were of analytical grade (AR).

\section{Experimental design ( $3^{2}$ full factorial design)}

To reduce the number of trials and attain the highest amount of information on product properties, the screening was done by applying full factorial design $\left(3^{2}\right)$, systematically study the joint influence of the independent variables on the dependent variables. So, in this study two factors were evaluated, each at three levels and experimental trials was performed at all nine possible combinations. Amount of phospholipid (PL90G-1, 2 and 3 moles) was taken as the first independent variable $\left(\mathrm{X}_{1}, \mathrm{w}\right)$ and amount of cholesterol ( $\mathrm{CH}-1,2$ and 3 moles) was selected as the second independent variables $\left(\mathrm{X}_{2}, \mathrm{w}\right)$ for liposomes. These variables varied at three levels, low level $(-1)$, medium level $(0)$, and high level $(+1)$.
All the calculations were done at milligram level. Amount of PT (10 $\mu \mathrm{M})$ and final formulation volume $15 \mathrm{ml}$ was kept constant. Percent entrapment efficiency (\% EE) ( $\left.\mathrm{Y}_{1}\right)$ and percent in vitro drug release at $12 \mathrm{~h}(\% \mathrm{DR})\left(\mathrm{Y}_{2}\right)$ were selected as dependent variables. Values of variables and batch codes are shown in table 1 and 2. Design Expert $^{\circledR}$ DX 10.0.7.0 (Stat-Ease Inc., MN) license version software was used for the generation and evaluation of statistical experimental design [25-26].

\section{Preparation of paclitaxel-loaded liposomes (PTL)}

Liposomes were prepared by the thin film hydration method (TFH). The $10 \mu \mathrm{M}$ PT (mol. wt., 853.9) constant for all batches and the required quantities of phospholipid (PL90G) (mol. wt., 758.07) and cholesterol (CH) (mol. wt., 386.67) were taken in a $100 \mathrm{ml}$ round bottom flask and dissolved in $10 \mathrm{ml}$ chloroform. All the batches were prepared according to the experimental design in table 1 . Chloroform was evaporated using rotary vacuum evaporator (Model: PBV-7D, Vertical condenser, rotavap, superfit ${ }^{\mathrm{TM}}$ continental Pvt. Ltd., Mumbai, India) and kept overnight under vacuum. Then it was hydrated by $15 \mathrm{ml}$ of phosphate buffer $\mathrm{pH} 7.4$ for $1 \mathrm{~h}$ with 10 min of extensive vortexing. The suspension of liposomes was sonicated in the water bath at $60^{\circ} \mathrm{C}$ to reduce the size of liposomes. Non-incorporated PT was separated by ultracentrifuge at 10,000 rpm for $30 \mathrm{~min}$ at $4{ }^{\circ} \mathrm{C}$. The supernatant was then discarded and PT loaded liposomes in the precipitate were redispersed in required volume of phosphate buffer $\mathrm{pH}$ 7.4. This was transferred to vials and stored at $4{ }^{\circ} \mathrm{C}[27]$.

Table 1: $3^{2}$ full factorial design: factors, factor levels and responses for PTL formulation

\begin{tabular}{lll}
\hline Factors (Independent variables) & Factor levels used & Medium (0) \\
\cline { 2 - 3 } & Low (-1) & High (+1) \\
\hline Amount (moles) of phospholipid (PL90G) $\left(\mathrm{X}_{1}, \mathrm{w}\right)$ & 1 & 2 \\
Amount (moles) of cholesterol (CH) $\left(\mathrm{X}_{2}, \mathrm{w}\right)$ & 1 & 2 \\
Responses (Dependent variable) & & \\
$\mathrm{Y}_{1}=$ Percent entrapment efficiency (\% EE) & & \\
$\mathrm{Y}_{2}=$ Percent in vitro drug release (\% DR) & & \\
\hline
\end{tabular}

\section{Statistical analysis and optimization of formulation using RSM}

Response surface modeling and evaluation of the quality of fit of the model for the current study were performed employing Design Expert $^{\circledR}$ DX 10.0.7.0 license version software [23-26, 30]. Polynomial models including linear, interaction and quadratic terms were generated for all the response variables using multiple linear regression analysis (MLRA). A second-order polynomial equation that describes the effect of independent factors on the response is expressed in the following forms:

Linear model: $Y=\beta_{0}+b_{1} X_{1}+b_{2} X_{2}(1)$

2FI (interaction model): $Y=\beta_{0}+\beta_{1} X_{1}+\beta_{2} X_{2}+\beta_{12} X_{1} X_{2}(2)$

Quadratic model $=\beta_{0}+\beta_{1} X_{1}+\beta_{2} X_{2}+\beta_{12} X_{1} X_{2}+\beta_{11} X_{1}{ }^{2}+\beta_{22} X_{2}{ }^{2}(3)$

Where $Y$ is the dependent variable; $\beta_{0}$ is the arithmetic mean response of the nine runs and $\beta_{i}\left(\beta_{1} ; \beta_{2} ; \beta_{12} ; \beta_{11}\right.$ and $\left.\beta_{22}\right)$ is the estimated coefficient for the corresponding factor $X_{i}\left(X_{1}, X_{2}, X_{1} X_{2}\right.$, $\mathrm{X}_{1} \mathrm{X}_{1}$, and $\left.\mathrm{X}_{2} \mathrm{X}_{2}\right)$. The main effects $\left(\mathrm{X}_{1}\right.$ and $\left.\mathrm{X}_{2}\right)$ represent the average result of changing one factor at a time from its low to high value. The interaction terms $\left(\mathrm{X}_{1} \mathrm{X}_{2}\right)$ show how the response changes when two factors are simultaneously changed. The polynomial terms $\left(\mathrm{X}_{1}{ }^{2}\right.$ and $\mathrm{X}_{2}{ }^{2}$ ) are included to investigate nonlinearity. The equations enable the study of the effects of each factor and their interaction over the considered responses. The polynomial equations were used to draw conclusions after considering the magnitude of coefficients and the mathematical sign they carry, i.e. positive or negative. A positive sign signifies a synergistic effect, whereas a negative sign stands for an antagonistic effect. The best fitting mathematical model was selected based on the comparisons of several statistical parameters, including the coefficient of variation (CV), the coefficient of determination $\left(\mathrm{R}^{2}\right)$, adjusted coefficient of determination (Adjusted $\mathrm{R}^{2}$ ) and the predicted residual sum of square (PRESS), provided by
Design Expert software. Among them, PRESS indicates how well the model fits the data and for the chosen model it should be small relative to the other models under consideration. Level of significance was considered at $p<0.05$. Mathematical relationships in the form of polynomial equations are generated using multiple linear regression analysis (MLRA) and used to find out the relative influence of each factor on the response. Analysis of variance (ANOVA) for the responses was performed to identify a significant effect of factors on responses and the model parameters were obtained. The relationship between the dependent and independent variables was further elucidated using contour and response surface plots. Two-dimensional contour plots and three-dimensional response surface plots resulting from equations were obtained by the Design Expert software. These plots are very useful in a study of the effects of two factors on the response at one time and predict the responses of dependent variables at the intermediate levels of independent variables. Subsequently, a numerical optimization technique by the desirability and graphical optimization technique by the overlay plot approach were used to generate the new formulation with the desired responses. An optimized formulation was developed by setting constraints (goals) on the dependent and independent variables. To validate the chosen experimental design, the resultant experimental values of the responses were quantitatively compared with those of the predicted values and calculated the percent relative error (PRE) by the following equation 5 .

$$
\% \text { Relative error }=\frac{\text { Predicted value Experiment value }}{\text { Predicted value }} \times 100
$$

\section{Determination of percent entrapment efficiency (\% EE)}

Purification of PTL formulation was done by the ultracentrifugation method [28]. To quantify the amount of entrapped PT, $2 \mathrm{ml}$ of the vesicular dispersion was centrifuged at $10,000 \mathrm{rpm}$ for $1 \mathrm{~h}$ at the 
controlled temperature of $4{ }^{\circ} \mathrm{C}$ (Remi cooling centrifuge, Remi Elektrotechnik limited, India). Supernatant contains unentrapped drug was withdrawn and measured UV spectrophotometrically (at $\lambda \max -230 \mathrm{~nm}$ ) (Model: SPECTRO 2060 PLUS, Analytical Technologies Ltd., Gujarat, India) against 30:70 ratio of methanol: phosphate buffer solution (PBS) ( $\mathrm{pH}$ 7.4). All the determinations were made in triplicate. A calibration plot was produced by diluting stock solutions of PT with 30:70 ratio of methanol and PBS (pH 7.4). \% EE was calculated and expressed as a percent of the available dissolved solute actually encapsulated. The amount of drug entrapped in liposomes was determined by equation 1 .

$$
\% \text { entrapment efficiency }(\% \mathrm{EE})=\frac{\text { Amount of entrapped drug }}{\text { Total amount of drug }} \times 100
$$

Percent in vitro drug release study (\% DR) at $12 \mathrm{~h}$.

The in vitro drug release study for PT from different PTL formulation was carried out as per the procedure described by Utreja [29] with little modifications. In brief, the Franz diffusion cell apparatus was employed for this study. The apparatus is consisted of donor and receptor compartment, with an effective surface area for dissolution was $\left(2.303 \mathrm{~cm}^{2}\right)$. The dialysis membrane (LA395, Dialysis Membrane$110 \mathrm{AV}$, flat width $\sim 31.12 \mathrm{~mm}$, Average diameter $\sim 21.5 \mathrm{~mm}$, and approximate capacity is $\sim 3.63 \mathrm{ml} / \mathrm{cm}$; HI media laboratories, Mumbai, India) was employed and pretreated as per the directions were given by the manufacturer. After proper pretreatment, the membrane was cut into desired size and shape, then mounted between the effective surface area of donor and receptor compartment. The PTL dispersion $(2 \mathrm{ml})$ was placed over the membrane, accompanied by an addition of PBS $(20 \mathrm{ml}, \mathrm{pH} 7.4)$ contain $0.1 \%$ tween 80 as dissolution media in the receptor compartment. The contents of receptor compartment were stirred at $100 \mathrm{rpm}$ using magnetic stirrer at $37 \pm 1.0^{\circ} \mathrm{C}$. At specified time intervals, $2 \mathrm{ml}$ aliquots were withdrawn from sampling port of apparatus, diluted suitably with fresh media and the absorbance of the resulting solution was read at $230 \mathrm{~nm}$ using UV-visible spectrophotometer (Model: SPECTRO 2060 PLUS, Analytical Technologies Ltd., Gujarat, India).

\section{Vesicle morphology study of liposomes}

The liposomes were mounted on glass slides and viewed under a Motic Digital Microscope (type DM-1802) for morphological observation after suitable dilution. The size analysis of PTL was examined at the magnification of $(\times 40)$ using calibrated eyepiece micrometer. The images were recorded using Motic Image plus 2.0 ML software, accompanying with the instrument.

\section{Determination of percent drug content}

One milliliter of dispersion was pipette from the PTL formulation and lysed with methanol. It was further diluted with 30:70 ratio of methanol: phosphate buffer solution (PBS) ( $\mathrm{pH} 7.4$ ) and sample were analyzed spectrophotometrically at $\lambda \max 230 \mathrm{~nm}$ for PT. [26]

Determination of particle size, poly-dispersity index (PDI) and

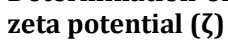

The size of liposomes was measured by dynamic light scattering with a Malvern zetasizer. Diluted (1:100) PTL dispersion was added to the sample cuvette and then cuvette is placed in zetasizer. The sample is stabilized for two minutes and reading was measured. The average particle size was measured after performing the experiment in triplicate. The zeta potential of developed PTL formulation was determined using Malvern zetasizer (Malvern zetasizer ver. 6.20, UK). The zeta potential was calculated by Helmholtz-Smoluchowski's equation from the electrophoretic mobility of liposomes at $25^{\circ} \mathrm{C}$ [26].

\section{RESULTS AND DISCUSSION}

Experimental design and data acquiring ( $3^{2}$ full factorial design)

Full factorial design $\left(3^{2}\right)$ was applied to optimize the PTL formulation. All nine batches of PTL were prepared according to the formulation variables as shown in table 2. Liposomes were obtained by the TFH method. RSM was exploited to estimate the influence of the molar ratio of PL90G and $\mathrm{CH}$ as independent variables and their interactions on the investigated responses (dependent variables; \% EE and $\%$ DR). This experiment was aimed to identify considerable factor effect influencing the formulation performance and to set up to their excellent levels for the desirability of responses shown in table 2 .

\section{Statistical analysis and optimization of formulation using RSM}

To evaluate the quantitative effects of factors $\left(\mathrm{X}_{1}\right.$ and $\left.\mathrm{X}_{2}\right)$ and their levels low $(-1)$, middle $(0)$, and high $(+1)$ on the preferred responses, the experimental values of the flux were analyzed by Design Expert ${ }^{\circledR}$ DX 10.0.7.0 license version software and mathematical models obtained for each response [25-26, 30-31]. The mathematical relationship generated using multiple linear regression analysis (MLRA) for the studied response variables (\% EE and \% DR at $12 \mathrm{~h}$.) that were relating different response and independent variables are expressed as following polynomial equations (quadratic model).

$\mathrm{Y}_{1}(\% \mathrm{EE})=76.63+3.10 \mathrm{X}_{1-}-9.44 \mathrm{X}_{2}+3.18 \mathrm{X}_{1} \mathrm{X}_{2-}-9.91 \mathrm{X}_{1}{ }^{2}+0.35 \mathrm{X}_{2}{ }^{2}(6)$

$\mathrm{Y}_{2}(\% \mathrm{DR} 12 \mathrm{~h})=.64.74+6.79 \mathrm{X}_{1}-4.63 \mathrm{X}_{2}-1.38 \mathrm{X}_{1} \mathrm{X}_{2}-15.29 \mathrm{X}_{1}{ }^{2}-5.82 \mathrm{X}_{2}{ }^{2}(7)$

The above equations expose the quantifiable effect of the independent variables, a molar ratio of PL90G and $\mathrm{CH}$, on the responses such as \% EE $\left(\mathrm{Y}_{1}\right)$ and in vitro \% DR at $12 \mathrm{~h}\left(\mathrm{Y}_{2}\right)$ as dependent variables. The fitted polynomial equation (quadratic model) related to \% $\mathrm{EE}$ and percent in vitro $\% \mathrm{DR}$ used to draw a conclusion after considering the coefficient and the mathematical sign it carries. i.e. positive and negative. The correlation coefficient $\left(r^{2}\right)$ of the quadratic model $(0.9736)$ for response $Y_{1}(\% \mathrm{EE})$ and $(0.9779)$ for response $Y_{2}(\%$ DR) was found to be significant.

\section{Response 1 (Percent entrapment efficiency) (\% EE)}

Regression analysis of above equation (6) of response $\mathrm{Y}_{1}(\% \mathrm{EE})$ revealed that the coefficient of $\beta_{1}$ was positive and $\beta_{2}$ was negative, this indicated that as PL90G $\left(\mathrm{X}_{1}\right)$ increased the \% EE increased but as we further increased the PL90G $\left(\mathrm{X}_{1}\right)$ to higher level the \% EE decreased and on increasing cholesterol $\left(\mathrm{X}_{2}\right)$ the \% EE decreased. The higher concentration of cholesterol leads to rigidity in the vesicles [26] which in turn decreased the \% EE. The \% EE of different liposomal batches was in a range of 51.68 to $86.67 \%$. The maximum entrapment was observed in batch L4 (table 2) with the composition of PL90G: CH (2:1 molar ratio) $(0,-1)$.

\begin{tabular}{|c|c|c|c|c|c|c|}
\hline \multirow[t]{2}{*}{ Batches } & \multicolumn{2}{|c|}{$\begin{array}{l}\text { Variable level in } \\
\text { coaded form }\end{array}$} & \multicolumn{2}{|c|}{ Variable level in actual form } & \multicolumn{2}{|l|}{ Response variables } \\
\hline & $\mathbf{X}_{1}$ & $\mathbf{X}_{2}$ & $\begin{array}{l}\text { Phospholipid (PL90G) } \\
\text { in moles }\left(\mathrm{X}_{1}, \mathrm{~W}\right)\end{array}$ & $\begin{array}{l}\text { Cholesterol }(\mathrm{CH}) \\
\text { in moles }\left(\mathrm{X}_{2}, \mathrm{~W}\right)\end{array}$ & $\begin{array}{l}\text { Percent entrapment } \\
\text { efficiency* }(\% \text { EE }) \pm S D\end{array}$ & $\begin{array}{l}\text { Percent In vitro drug release* } \\
(12 \text { h) }(\% \text { DR }) \pm S D\end{array}$ \\
\hline L1 & -1 & -1 & 1 & 1 & $75.65 \pm 1.48$ & $40.28 \pm 1.58$ \\
\hline L2 & -1 & 0 & 1 & 2 & $64.23 \pm 0.82$ & $43.68 \pm 0.98$ \\
\hline L3 & -1 & +1 & 1 & 3 & $51.68 \pm 0.75$ & $32.39 \pm 1.02$ \\
\hline L4 & 0 & -1 & 2 & 1 & $86.67 \pm 0.67$ & $63.49 \pm 1.21$ \\
\hline L5 & 0 & 0 & 2 & 2 & $78.69 \pm 1.61$ & $62.12 \pm 0.63$ \\
\hline L6 & 0 & +1 & 2 & 3 & $65.23 \pm 1.17$ & $56.98 \pm 1.33$ \\
\hline L7 & +1 & -1 & 3 & 1 & $77.12 \pm 1.53$ & $56.32 \pm 1.42$ \\
\hline L8 & +1 & 0 & 3 & 2 & $67.16 \pm 0.91$ & $57.85 \pm 0.87$ \\
\hline L9 & +1 & +1 & 3 & 3 & $65.89 \pm 1.32$ & $42.92 \pm 1.19$ \\
\hline
\end{tabular}

Table 2: Composition $3^{2}$ full factorial design with measured responses of PTL formulation

*Values represented as mean $\pm \mathrm{SD}, n=3$, All baches contain drug $10 \mu \mathrm{M}$ and $15 \mathrm{ml}$ phosphate buffer (pH 7.4) for hydration. 
Table 3: Analysis of variance (ANOVA) table of \% EE

\begin{tabular}{llllll}
\hline Source & Sum of squares & df & Mean squares & F Value & p-value Prob>F \\
\hline Model & 829.57 & 5 & 165.91 & 22.14 & 0.0142 \\
X $_{1}$-Phospholipid (PL90G) & 57.72 & 1 & 57.72 & 7.70 & 0.0692 \\
$\mathrm{X}_{2}$-Cholesterol (CH) & 534.68 & 1 & 534.68 & 71.36 & 0.0035 \\
$\mathrm{X}_{1} \mathrm{X}_{2}$ & 40.58 & 1 & 40.58 & 5.42 & 0.1024 \\
$\mathrm{X}_{1}{ }^{2}$ & 196.35 & 1 & 196.35 & 26.20 & 0.0144 \\
$\mathrm{X}_{2}{ }^{2}$ & 0.24 & 1 & 0.24 & 0.032 & 0.8693 \\
Residual & 22.48 & 3 & 7.49 & & \\
Cor-total & 852.05 & 8 & & & \\
\hline
\end{tabular}

For estimation of the significance of the model, the analysis of variance (ANOVA) was executed, from the ANOVA data, the model F-value of response $\left(\mathrm{Y}_{1}\right)(22.14)$ indicated that the model is significant shown in table 3 . There is only a $1.42 \%$ chance that an F-value this large could occur due to noise. Values of "prob $>F$ " less than 0.0500 indicate model terms are significant. In these case $\mathrm{X}_{2}, \mathrm{X}_{1}{ }^{2}$ are significant model terms. Values greater than 0.1000 indicate that model terms are not significant.

Table 4: Parameter of selected quadratic model of \% EE

\begin{tabular}{llll}
\hline Std. dev. & $\mathbf{2 . 7 4}$ & R-squared $\left(\boldsymbol{r}^{2}\right)$ & $\mathbf{0 . 9 7 3 6}$ \\
\hline Mean & 70.26 & Adjusted R-Squared & 0.9296 \\
C. V. $\%$ & 3.90 & Predicted R-Squared & 0.7315 \\
PRESS & 228.77 & Adequate Precision & 15.693 \\
\hline
\end{tabular}

The predicted R-squared value of 0.7315 is in reasonable agreement with the adjusted R-squared of 0.9296 ; i.e. the difference is less than 0.2 . Adequate precision measures the signal to noise ratio. A ratio greater than 4 is desirable and the result of adequate precision was 15.693 indicates an adequate signal. So, this model can use to navigate the design space.

The relationship between the dependent and independent variables was further elucidated using contour and response surface plots. The contour (fig. 1) and 3D response surface plots (fig. 2) of \% EE clearly indicated that $\mathrm{X}_{1}$ and $\mathrm{X}_{2}$ highly influenced the response 1 (\%
EE). The change in $\% \mathrm{EE}$ as a function of $\mathrm{X}_{1}$ and $\mathrm{X}_{2}$ was depicted in the form of contour and response surface plots based on full factorial design $\left(3^{2}\right)$. So, middle level of $X_{1}$ and low level of $X_{2}$ was found to be favorable conditions for obtaining higher $\% \mathrm{EE}$.
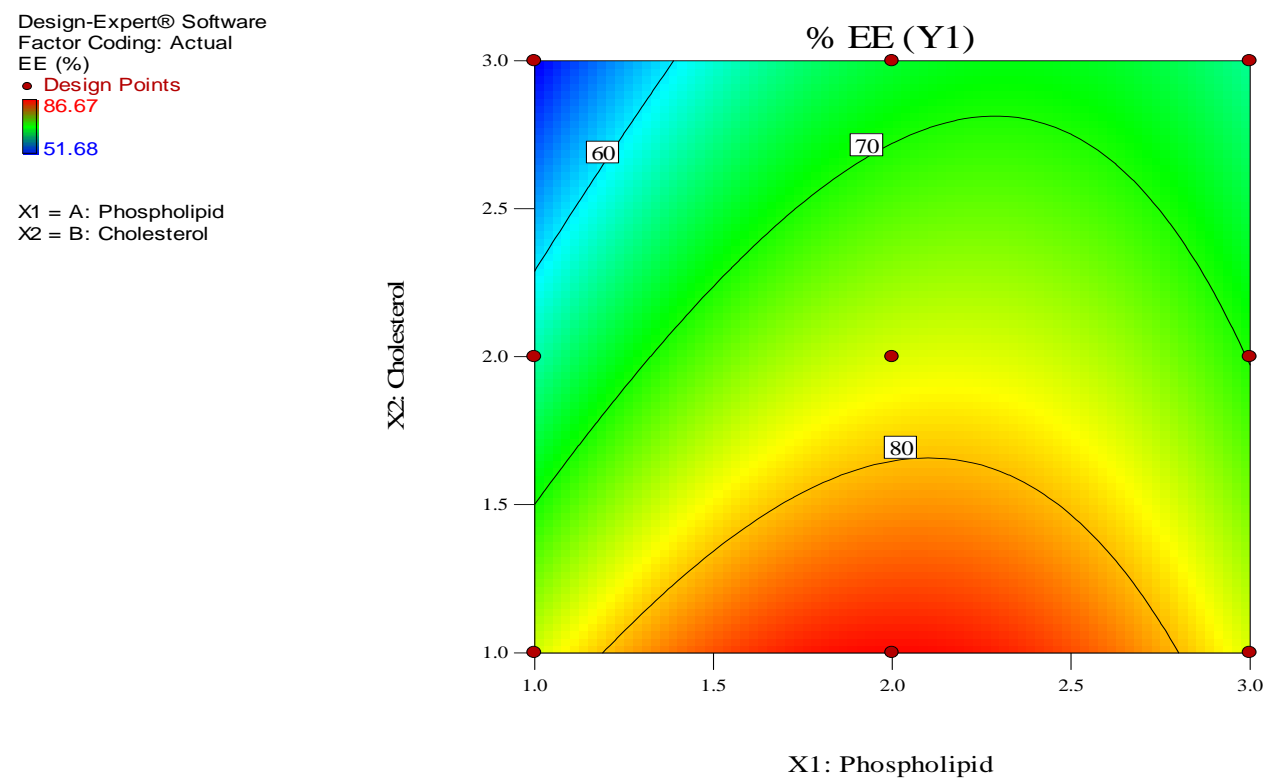

Fig. 1: Counter plot showing the effect of phospholipid (PL90G) $\left(\mathrm{X}_{1}\right)$ and cholesterol $(\mathrm{CH})\left(\mathrm{X}_{2}\right)$ on \% EE ( $\left.\mathrm{Y}_{1}\right)$ of PTL

\section{Response 2 (Percent drug release at $12 \mathrm{~h})(\% \mathrm{DR})$}

The effect on drug release at $12 \mathrm{~h}(\% \mathrm{DR})\left(\mathrm{Y}_{2}\right)$ was observed to be significant $(\mathrm{P}<0.05)$ by ANOVA and the polynomial equation $(7)$ revealed that the coefficient of $\beta_{1}$ was positive and $\beta_{2}$ was negative, this indicated that as PL90G $\left(\mathrm{X}_{1}\right)$ increased the \% DR increased and on increasing cholesterol $\left(\mathrm{X}_{2}\right)$ the \% DR decreased. The \% DR increased with increased concentration of lipid and at a certain level the percent release is retarded above that and the release was decreased at higher levels of cholesterol. This is because cholesterol at higher levels makes the lipid bilayers more rigid and retards the release of the drug. This was evident by the higher cholesterol concentration of vesicles showed around $50 \%$ of the release except for (L6) formulations. The L4 formulation found to have $63.43 \% \mathrm{DR}$ at $12 \mathrm{~h}$ (table 2) with the composition of PL90G: $\mathrm{CH}$ (2:1 molar ratio) $(0,-1)$. At lower concentration of phospholipid and cholesterol, the drug release was very less due to the formation of stagnant layer [26]. 


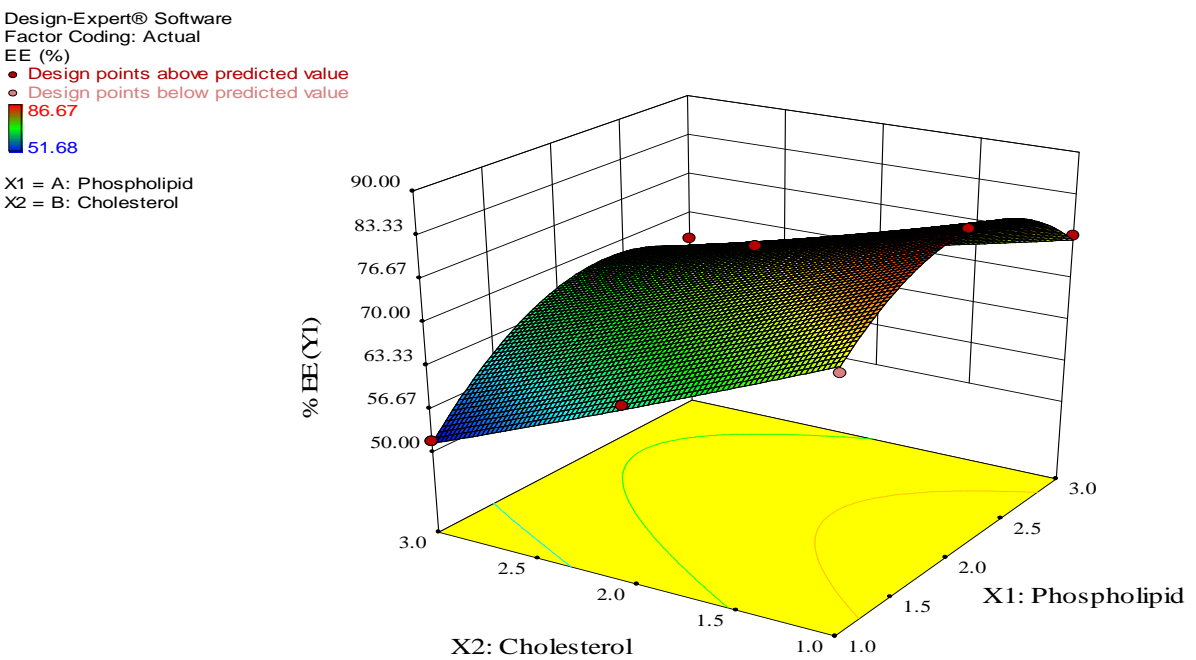

Fig. 2: Response surface plot showing the effect of phospholipid (PL90G) $\left(\mathrm{X}_{1}\right)$ and cholesterol (CH) ( $\left.\mathrm{X}_{2}\right)$ on \% EE (Y $\left.\mathrm{Y}_{1}\right)$ of PTL

Table 5: Analysis of variance (ANOVA) table of $\%$ DR at $12 \mathrm{~h}$

\begin{tabular}{llllll}
\hline Source & Sum of squares & df & Mean squares & F Value & p-value prob>F \\
\hline Model & 948.33 & 5 & 189.67 & 26.53 & 0.0109 \\
A-Phospholipid & 276.62 & 1 & 276.62 & 38.70 & 0.0084 \\
B-Cholesterol & 128.81 & 1 & 128.81 & 18.02 & 0.0239 \\
AB & 7.59 & 1 & 7.59 & 1.06 & 0.3786 \\
A $^{2}$ & 467.57 & 1 & 467.57 & 65.41 & 0.0040 \\
B $^{2}$ & 67.74 & 1 & 67.74 & 9.48 & 0.0542 \\
Residual & 21.44 & 3 & 7.15 & & \\
Cor Total & 969.78 & 8 & & & \\
\hline
\end{tabular}

From the ANOVA data, the model F-value of response $\left(\mathrm{Y}_{2}\right)(26.53)$ indicated that the model is significantly shown in table 5 . There is only a 1.09\% chance that a model F-value this large could occur due to noise. Values of "prob>F" less than 0.0500 indicate model terms are significant. In these case, $\mathrm{X}_{1}, \mathrm{X}_{2}$, and $\mathrm{X}_{1}^{2}$ are significant model terms. Values greater than 0.1000 indicate that model terms are not significant.

Table 6: Parameter of selected quadratic model of \% DR at $12 \mathrm{~h}$

\begin{tabular}{llll}
\hline Std. Dev. & $\mathbf{2 . 6 7}$ & R-squared $\left(\boldsymbol{r}^{\mathbf{}}\right)$ & $\mathbf{0 . 9 7 7 9}$ \\
\hline Mean & 50.67 & Adjusted R-Squared & 0.9410 \\
C. V. \% & 5.28 & Predicted R-Squared & 0.8063 \\
PRESS & 187.85 & Adequate Precision & 14.272 \\
\hline
\end{tabular}

The predicted R-squared value of 0.8063 is in reasonable agreement with the adjusted R-squared of 0.9410 ; i.e. the difference is less than 0.2 . Adequate precision measures the signal to noise ratio. A ratio greater than 4 is desirable and result of adequate precision was 14.272 indicates an adequate signal. So, this model can be used to navigate the design space.

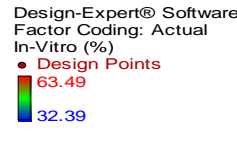

X1 $=$ A: Phospholipid
X2 = B: Cholesterol

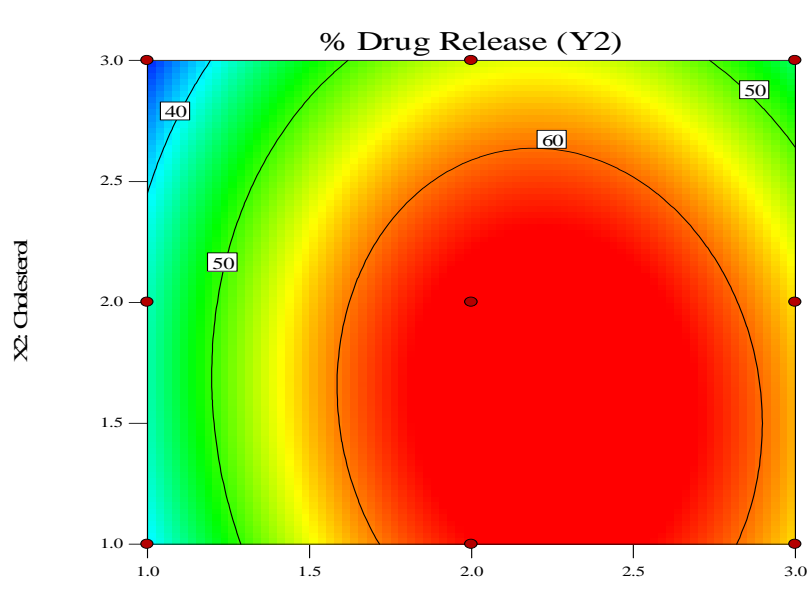

X1: Phospholipid

Fig. 3: Counter plot showing the effect of phospholipid (PL90G) $\left(\mathrm{X}_{1}\right)$ and cholesterol $(\mathrm{CH})\left(\mathrm{X}_{2}\right)$ on \% DR at $12 \mathrm{~h}\left(\mathrm{Y}_{2}\right)$ of PTL 


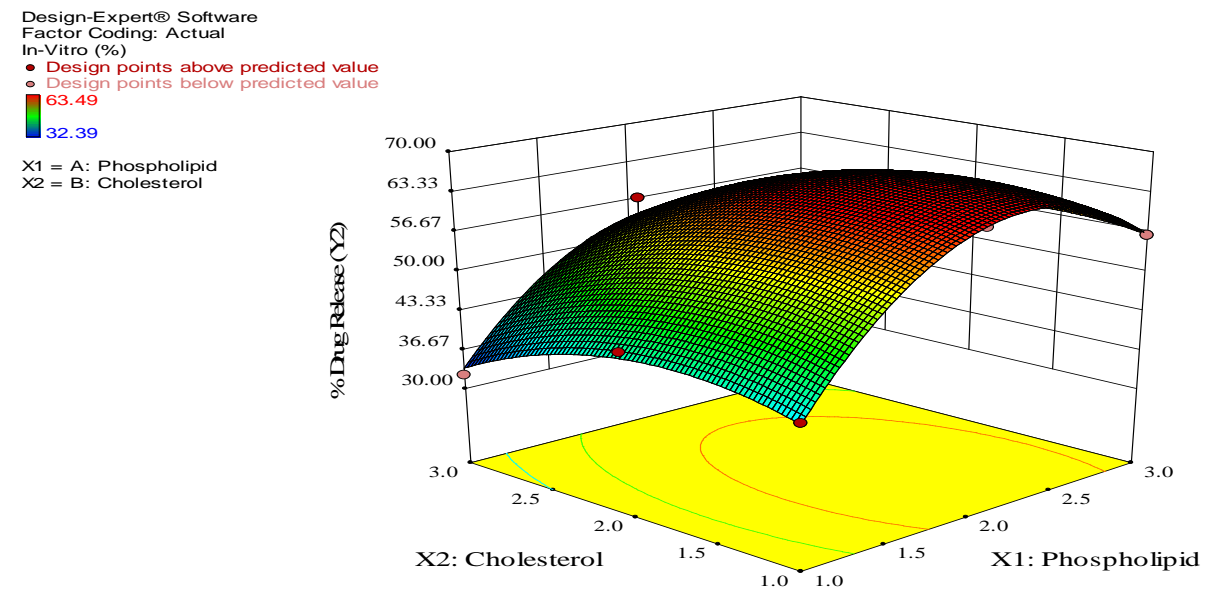

Fig. 4: Response surface plot showing the effect of phospholipid (PL90G) $\left(\mathrm{X}_{1}\right)$ and cholesterol (CH) ( $\left.\mathrm{X}_{2}\right)$ on \% DR at $12 \mathrm{~h}\left(\mathrm{Y}_{2}\right)$ of PTL

To envisage the effect of an independent factor on the response $\left(\mathrm{Y}_{2}\right)$ the contour plot (fig. 3) and 3D-response surface plots (fig. 4) of \% $\mathrm{DR}$ at $12 \mathrm{~h}$ shows the curvature with a change in the factor $\left(\mathrm{X}_{1}\right.$ and $\mathrm{X}_{2}$ ). The plot was found to be curvilinear and indicated that a high value of \% DR (63.43\%) can be obtained for a combination middle level of $\mathrm{X}_{1}$ and low level of $\mathrm{X}_{2}$ factors.

\section{Desirability and overlay plot}

The aim of pharmaceutical formulation optimization is generally to find the levels of the variable that affect the chosen responses and determine the levels of the variable from which a robust product with high-quality characteristics may be produced. All the measured responses that may affect the quality of the product were taken into consideration during the optimization procedure. The $\% \mathrm{EE}$ and \% DR at $12 \mathrm{~h}$ were set out in the maximum criteria. Each response criterion was combined (overlay plot) to obtain the optimum value (fig. 5). The optimization results of this research can be seen in table 7 .

\section{Validation of RSM results}

In order to evaluate the optimization capability of models generated according to the results of the RSM ( $3^{2}$ full factorial design), PTL formulation was prepared using the optimal process variables settings that $X_{1}$ and $X_{2}$ were equal to 2:1. The response $Y_{1}(\% \mathrm{EE})$ and $Y_{2}(\% \mathrm{DR}$ at $12 \mathrm{~h}$ ) obtained with predicted models and the experimental model were shown in table 8 . The percent relative error was obtained using equation 4. The percent relative error (PRE) for response $\mathrm{Y}_{1}$ (\% EE) and $Y_{2}(\%$ DR at $12 \mathrm{~h})$ were found to be $(-0.290)$ and $(0.058)$ respectively. The maximum PRE value was $(-0.290)$. However, the values were found to be $<2 \%$ and hence it confirmed the suitability of experimental design. The results showed good agreement on preparation properties with theoretical properties.

Table 7: Characteristics of optimum formula

\begin{tabular}{llllll}
\hline Objects & $\begin{array}{l}\text { Phospholipid (PL90G) } \\
\text { in moles }\left(\mathbf{X}_{\mathbf{1}}, \mathbf{W}\right)\end{array}$ & $\begin{array}{l}\text { Cholesterol }(\mathbf{C H}) \\
\text { in moles }\left(\mathbf{X}_{\mathbf{2}}, \mathbf{W}\right)\end{array}$ & $\begin{array}{l}\mathbf{\%} \mathbf{E E} \\
\left(\mathbf{Y}_{\mathbf{1}}, \mathbf{\%}\right)\end{array}$ & $\begin{array}{l}\text { In vitro \% DR at 12 } \mathbf{~ h} \\
\left(\mathbf{Y}_{\mathbf{2}}, \mathbf{\%}\right)\end{array}$ & Desirability \\
\hline Predicted & 1.996 & 1.000 & 86.419 & 63.527 & 0.996 \\
Actual (L4) & 2 & 1 & $86.67 \pm 0.67$ & $63.49 \pm 1.21$ & Selected \\
\hline
\end{tabular}

The optimization parameter of desirability was determined by regulating the optimum input variables to obtain one or more optimal parameters. The desirability value ranged between 0 and 1 , where a value of 1 is perfect, i.e., the ideal parameter value [30]. The PTL desirability plot was shown in fig. 6. The optimizing desirability of PTL formulation was 0.996 . This value was near to ideal value (1), meaning that the predicted parameters were desired parameter values. The composition of the predicted formulations was matching with L4 liposomes (table 7).

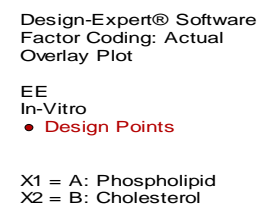

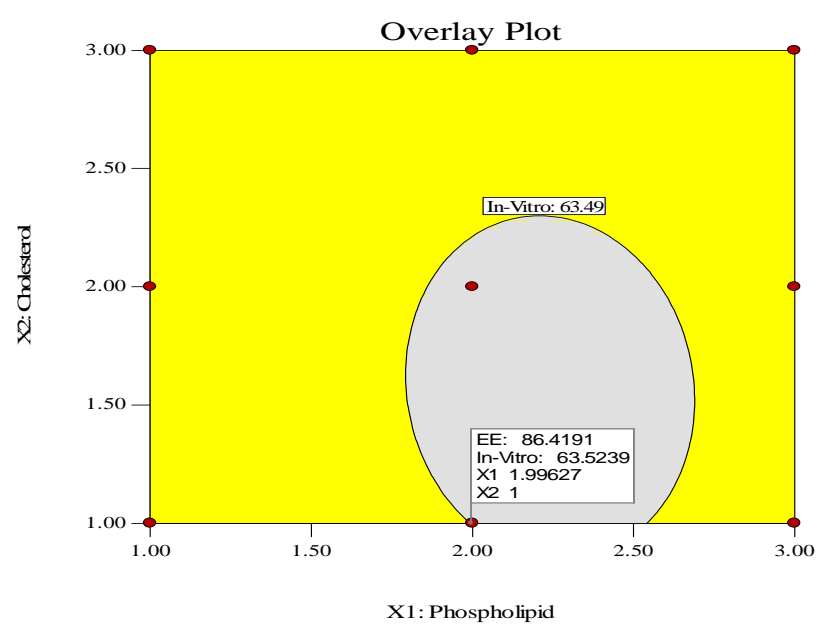

Fig. 5: Overlay plot of \% EE and \% DR at $12 \mathrm{~h}$ 


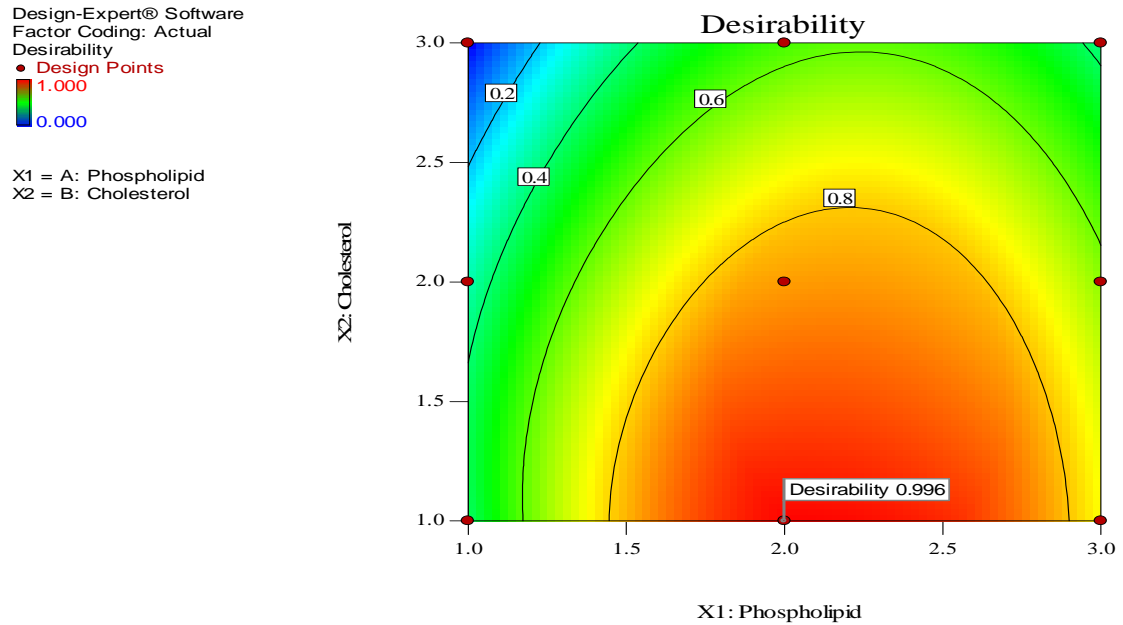

Fig. 6: PTL desirability plot

Table 8: Validation of predicted and experimental PTL batch

\begin{tabular}{llll}
\hline Response & Experimental values & Predicted value & \% Relative error (PRE) \\
\hline $\mathrm{Y}_{1}(\% \mathrm{EE})$ & $86.67 \pm 0.67$ & 86.419 & -0.290 \\
$\mathrm{Y}_{2}(\% \mathrm{DR}$ at $12 \mathrm{~h})$ & $63.49 \pm 1.21$ & 63.527 & 0.058 \\
\hline
\end{tabular}

Vesicle morphology, percent drug content, particle size, PDI and

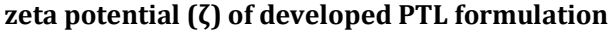

Vesicle morphology of developed PTL formulation was observed by Motic Digital Microscope (type DM-1802). The liposomes were spherical in shape with a smooth surface shown in fig. 7.
The developed liposomal percent drug content was found to be $98 \pm 1.0 \%$. (mean $\pm S D, n=3$ ). Percent drug content indicated that the PT was uniformly distributed in vesicular dispersions and percent drug content near to $100 \%$ indicated no loss of the material during the preparation.

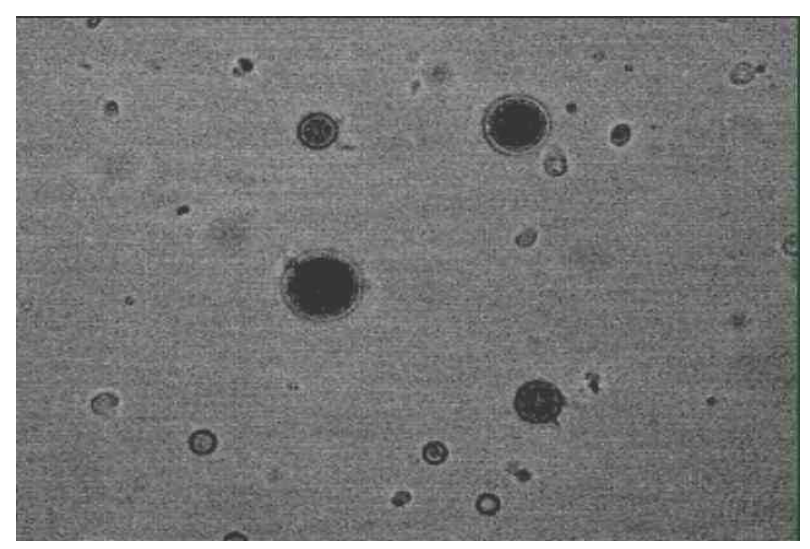

Fig. 7: Microphotograph of PTL by motic image plus 2.0 ML software
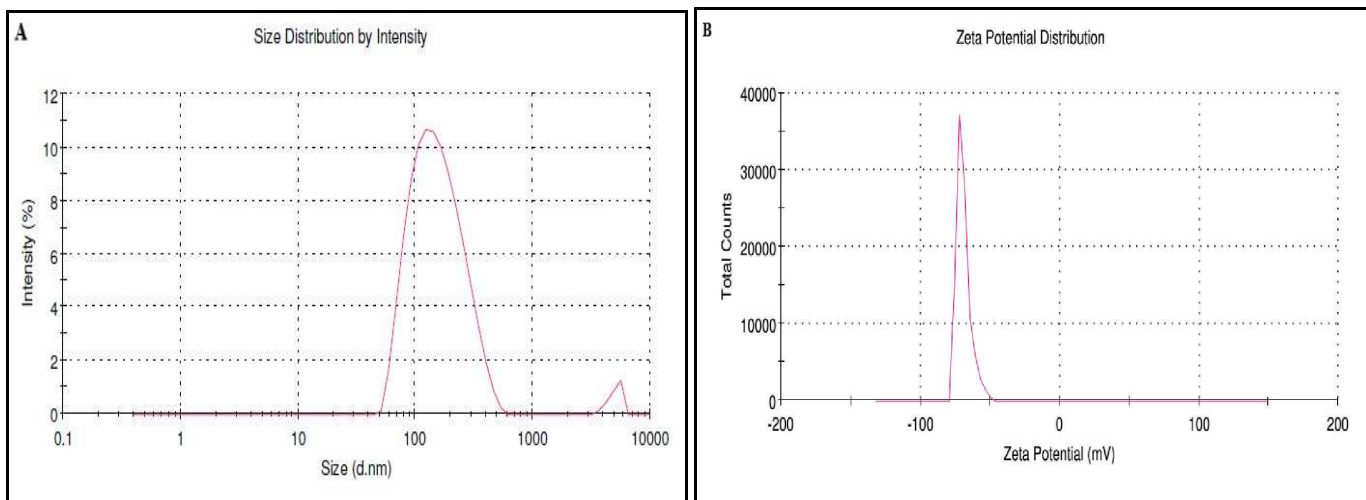

Fig. 8: The particle size (A) and Zeta potential (B) of developed PTL formulation 
The particle size (fig. 8A) and (ל) zeta potential (fig. 8B) of developed PTL formulation was found to be $144.4 \mathrm{~nm}$ and $(-) 22.6 \mathrm{mV}$. The polydispersity index was calculated as 0.224 . The low polydispersity index indicates a narrow range of particle size distribution. The zeta potential was a reliable indicator in the prediction of stability of particles in a liquid medium and the possible interactions with other materials. The behavior (size and size distribution) of vesicles completely depended on the amount of selected variables were also reported [32].

\section{CONCLUSION}

In the present study, the response surface methodology i.e. $3^{2}$ full factorial design was successfully employed for the optimization of PTL formulations. The PTL was prepared by thin film hydration method. The results of above optimization study displayed that the phospholipids (PL90G) and cholesterol (CH) with a molar ratio (2:1) showed an enhancement in rate and extent of in vitro release of PT from design-optimized PTL formulations. Thus, we conclude that the proposed RSM could be useful for the preparation and optimization of paclitaxel-based liposomal formulations.

\section{ACKNOWLEDGEMENT}

The authors wish to express their thanks and gratitude to University Dept. of Pharmaceutical Sciences, RTM Nagpur University, Nagpur and SKB College of Pharmacy, Kamptee, Nagpur for providing all necessary facilities for completion of this project work.

\section{AUTHORS CONTRIBUTION}

This work was carried out in collaboration between all the four authors in the concept and design of the work, collection, assembly, analysis and interpretation of data, writing, critical revision and approval of the final manuscript.

\section{CONFLICT OF INTERESTS}

All authors have none to declare

\section{REFERENCES}

1. Louage B, De Wever O, Hennink WE, De Geest BG. Developments and future clinical outlook of taxane nanomedicines. J Controlled Release 2017;253:137-52.

2. Ye J, Liu Y, Xia X, Meng L, Dong W, Wang R, et al. Improved safety and efficacy of a lipid emulsion loaded with a paclitaxelcholesterol complex for the treatment of breast tumors. Oncol Rep 2016;36:399-409.

3. Kampan NC, Madondo MT, McNally OM, Quinn M, Plebanski M. Paclitaxel and its evolving role in the management of ovarian cancer. BioMed Res Int 2015:1-21. http://dx.doi.org/10.1155/2015/413076

4. Wang L, Yu RS, Yang WL, Luan SJ, Qin BK, Pang XB, et al. Effects of paclitaxel loaded-drug micelles on cell proliferation and apoptosis of human lung cancer A549 cells. Acta Pharma Sin 2015;50:1240-5.

5. Lemstrova R, Melichar B, Mohelnikova-Duchonova B. Therapeutic potential of taxanes in the treatment of metastatic pancreatic cancer. Cancer Chemother Pharmacol 2016;78:1101-11.

6. Webster LK, Woodcock DM, Rischin D, Millward MJ. Review: cremophor: the pharmacological activity of an" inert" solubiliser. J Oncol Pharm Pract 1997;3:186-92.

7. Cragun JM, Baggs JH, Rollins C, Chambers SK. Case report hypersensitivity reaction to parenteral nutrition after severe hypersensitivity reaction to paclitaxel. Am J Clin Exp Obstet Gynecol 2013;1:69-75.

8. Singla AK, Garg A, Aggarwal D. Paclitaxel and its formulations. Int J Pharm 2002;235:179-92.

9. Moes J, Koolen S, Huitema A, Schellens J, Beijnen J, Nuijen B. Development of an oral solid dispersion formulation for use in low-dose metronomic chemotherapy of paclitaxel. Eur J Pharm Biopharm 2013;83:87-94.

10. Sandhu PS, Beg S, Mehta F, Singh B, Trivedi P. Novel dietary lipid-based self-nano emulsifying drug delivery systems of paclitaxel with p-gp inhibitor: implications on cytotoxicity and biopharmaceutical performance. Expert Opin Drug Delivery 2015;12:1809-22.
11. Li J, Wang F, Sun D, Wang R. A review of the ligands and related targeting strategies for active targeting of paclitaxel to tumours. J Drug Target 2016;24:590-602.

12. Xu J, Zhang $X$, Chen $Y$, Huang $Y$, Wang $P$, Wei $Y$, et al. Improved micellar formulation for enhanced delivery for paclitaxel. Mol Pharm 2016;14:31-41.

13. Bonde S, Nair S. Advances in liposomal drug delivery system: fascinating types and potential applications. Int J Appl Pharm 2017;9:1-7.

14. Li J, Huang P, Chang L, Long X, Dong A, Liu J, et al. Tumor targeting and $\mathrm{pH}$-responsive polyelectrolyte complex nanoparticles based on hyaluronic acid-paclitaxel conjugates and chitosan for oral delivery of paclitaxel. Macromol Res 2013;21:1331-7.

15. Teow HM, Zhou Z, Najlah M, Yusof SR, Abbott NJ, D'Emanuele A. Delivery of paclitaxel across cellular barriers using a dendrimer-based nanocarrier. Int J Pharm 2013;441:701-11.

16. Al-Najjar BY, Hussain SA. Chitosan microspheres for the delivery of chemotherapeutic agents: paclitaxel as a model. Asian J Pharm Clin Res 2017;10:1-5.

17. Kulkarni PR, Yadav JD, Vaidya KA. Liposomes: a novel drug delivery system. Int J Curr Pharm Res 2011;3:10-8.

18. Zhang W, Wang G, Falconer JR, Baguley BC, Shaw JP, Liu J, et al. Strategies to maximize liposomal drug loading for a poorly water-soluble anticancer drug. Pharm Res 2015;32:1451-61.

19. Zhang H, Gong W, Wang ZY, Yuan SJ, Xie XY, Yang YF, et al. Preparation, characterization, and pharmacodynamics of thermosensitive liposomes containing docetaxel. J Pharm Sci 2014;103:2177-83.

20. Bhatia A, Singh B, Raza K, Shukla A, Amarji B, Katare OP. Tamoxifen-loaded novel liposomal formulations: evaluation of anticancer activity on DMBA-TPA induced mouse skin carcinogenesis. J Drug Target 2012;20:544-50.

21. Carbone C, Tomasello B, Ruozi B, Renis M, Puglisi G. Preparation and optimization of PIT solid lipid nanoparticles via statistical factorial design. Eur J Med Chem 2010;49:110-7.

22. Hermans K, Van den Plas D, Everaert A, Weyenberg W, Ludwig A. Full factorial design, physicochemical characterisation and biological assessment of cyclosporine loaded cationic nanoparticles. Eur J Pharm Biopharm 2012;82:27-35.

23. Krishnaiah D, Bono A, Sarbatly R, Nithyanandam R, Anisuzzaman SM. Optimisation of spray drying operating conditions of Morinda citrifolia L. Fruit extracts using response surface methodology. J King Saud Univ 2012;27:26-36.

24. Minitab. What is a Response Surface Design; 2016. Available from: http://www.support.minitab.com/en-us/minitab/17/ topic-library/modeling-statistics/doe/response-surfacedesigns/what-is-a-response-surface-design. [Last accessed on 10 Nov 2017].

25. Ghanbarzadeh S, Valizadeh H, Zakeri Milani P. Application of response surface methodology in the development of sirolimus liposomes prepared by thin film hydration technique. Biolmpacts 2013;3:75-81.

26. Sudhakar B, Krishna MC, Murthy KV. Factorial design studies of antiretroviral drug-loaded stealth liposomal injectable: PEGylation, lyophilization and pharmacokinetic studies. Appl Nanosci 2016;6:43-60.

27. Dua JS, Rana AC, Bhandari AK. Liposome: methods of preparation and applications. Int J Pharm Stud Res 2012;3:14-20.

28. Yang T, Cui FD, Choi MK, Lin H, Chung SJ, Shim CK, et al. Liposome formulation of paclitaxel with enhanced solubility and stability. Drug Delivery 2007;14:301-8.

29. Utreja P, Jain S, Tiwary AK. Localized delivery of paclitaxel using elastic liposomes: Formulation development and evaluation. Drug Delivery 2011;18:367-76.

30. Damai RS, Silvia S, Etik M. Optimization of luteolin-loaded transfersome using response surface methodology. Int J Appl Pharm 2017;9(Suppl):107-11.

31. Majumdar S, Debnath R, Bhattacharjee A, Banerjee A, Patro CS. Statistical optimization and characterization of prepared Fluconazole topical liposomal gel for improved skin permeation. Pelagia Res Lib 2014;5:42-55.

32. Tatode AA, Patil AT, Umekar MJ, Telange DR. Investigation of effect of phospholipids on the physical and functional characterization of paclitaxel liposomes. Int J Pharm Pharm Sci 2017;9:141-6. 